\title{
Experimental Study on an Novel Environment-Friendly Coagulant for Treating Drinking Water
}

\author{
Defang Zeng', Wen Qin ${ }^{2}$ \\ ${ }^{1}$ School of Resource and Environmental Engineering, Wuhan University of Technology, Wuhan, China; ${ }^{2}$ Hubei Key Laboratory of \\ Mineral Resource Processing and Environment, Wuhan, China. \\ Email: qinwen0514@163.com, 549324291@qq.com
}

Received March $2^{\text {nd }}, 2012$; revised March 31 $1^{\text {st }}$ 2012; accepted April 30 ${ }^{\text {th }}, 2012$

\begin{abstract}
An environment-friendly composite coagulant for treating drinking water was prepared by using $\left[\mathrm{Al}_{2}(\mathrm{OH})_{\mathrm{n}} \mathrm{Cl}_{6-\mathrm{n}}\right] \mathrm{m} \cdot\left[\mathrm{Fe}_{2}(\mathrm{OH})_{\mathrm{N}} \mathrm{Cl}_{6-\mathrm{N}}\right] \mathrm{M}$ (PAFC), chitosan (CTS) and modified starch (MS). It is called PCS. Results indicated that the best proportion of this coagulant was $\mathrm{V}(0.1 \mathrm{wt} \%$ PAFC): $\mathrm{V}(0.001 \mathrm{wt} \% \mathrm{CTS}): \mathrm{V}(3 \mathrm{wt} \%$ modified starch $)=$ 25:6:8. If compared with using traditional coagulant such as PAC, adding the novel coagulant, turbidity and the mass concentration of $\mathrm{Al}^{3+}$ in the water were decreased by $5.17 \%$ and $51.1 \%$ respectively. Rapid and slow stirring speed in Jar test were evaluated and they were founded to be slight influence. And neutral $\mathrm{pH}$ and room temperature allow up to $97.2 \%$ turbidity removal. Low coagulant doses reached high turbidity removal percentage, so this coagulant has obvious economic and environmental benefits.
\end{abstract}

Keywords: Drinking Water; Aluminum Ion; Coagulant

\section{Introduction}

Potable water is the most precious resource [1], so it is an important task to research on drinking water treatment. Water treatment for human consumption is a technically overcome issue in developed countries, but it is still a lethal difficulty in less developed regions. Coagulation is the commonly used method for purifying water [2]. With the mature technology, polyaluminium chloride (PAC) has large market demand as the water treatment coagulant in the world $[3,4]$. However, its secondary pollution is bad for people's health. For instance, aluminum ions produced by PAC hydrolysis will lead the person who drink this kind of water suffer from anemia, hair loss and brain dementia .In addition, it has been found to be a risk factor in Alzheimer's and other disease [5]. The drinking water quality standard of stacking-type permission content is $0.1 \mathrm{mg}-\mathrm{Al} / \mathrm{L}$ in the western developed countries while higher than $0.2 \mathrm{mg}-\mathrm{Al} / \mathrm{L}$ in many other countries. Therefore, the important issue urgently to be solved in water treatment field is how to develop new environmental coagulants with satisfactory coagulation effect and little secondary pollution. Because its effect better than a single coagulant. Composite flocculating agent becomes a hotspot of current researches. Nowadays, the synergy between inorganic and organic chemicals is of growing interest. This synergy can be obtained by using two components, or three and even more [6,7].
By using $\left[\mathrm{Al}_{2}(\mathrm{OH})_{\mathrm{n}} \mathrm{Cl}_{6-\mathrm{n}}\right] \mathrm{m} \cdot\left[\mathrm{Fe}_{2}(\mathrm{OH})_{\mathrm{N}} \mathrm{Cl}_{6-\mathrm{N}}\right] \mathrm{M}(\mathrm{PAFC})$, chitosan (CTS), modified starch (MS) etc potions as raw materials, a new water treatment compound flocculating agent was developed. Chitosan (CTS), a deacetylated form of chitin [8], is the third-largest developing biological resource following the starch, cellulose [9]. The raw materials for preparing CTS is abundant, non-toxic and easily biodegradable [10]. Starch resources are rich, and the modified starch has better adsorption performance, so it has wide application prospects in water treatment field. The chitosan itself is a good natural flocculating agent [11]. The current investigation keeps on the direction: treating face water to improve its quality and make it more adequate to human consumption. The aim of this study was to investigate and characterize the effect of PCS as a novel, environmentally friendly composite coagulant.

\section{Material and Method}

\subsection{Raw Water}

The raw water was collected from the Yangtze Water in Wuhan, China. This choice of studying an actual surface water avoided the need to simulate turbidity with different physicochemical procedures, such as kaolin addition. The average characteristics of the raw water are given in Table 1. 
Table 1. Raw water characterization.

\begin{tabular}{lcc}
\hline Parameter & Value & Units \\
\hline Turbidity & $70-260$ & NTU \\
$\mathrm{pH}$ & $5-9$ & \\
Temperature & $10-30$ & ${ }^{\circ} \mathrm{C}$ \\
The concentration of $\mathrm{Al}^{3+}$ & $1.0-1.1$ & $\mathrm{mg} \cdot \mathrm{L}^{-1}$ \\
\hline
\end{tabular}

\subsection{Chemicals}

PAFC, PAC and PFS were produced by Nanjing Fine Chemical Company of China. CTS (the concentration of $\mathrm{Al}_{2} \mathrm{O}_{3}$ is about $0.3 \mathrm{~g} / \mathrm{g}$ ) was obtained from Qingdao Biochemical Company of China. Al-pillared montmorillonite $3 \mathrm{wt} \%$ was purchased from Zhongxiang, Hubei, China. Glacial acetic acid was supplied by Chemical Plant of Hubei University. Aluminum single element standard solution is $100 \mathrm{mg} / \mathrm{L}$ according to the national standard material center. All chemicals are of analysis pure grade.

\subsection{The Preparation of Single Coagulant Working Liquid}

The PAFC was diluted with water to prepare $0.1 \mathrm{wt} \%$ PAFC water-soluble working liquid. This formed solution was stirred for 5 minutes at room temperature. A few powder chitosan was dissolved it in glacial acetic acid and distilled water. Prepare $0.001 \mathrm{wt} \%$ CTS water-soluble working liquid. Prepare $3 \mathrm{wt} \% \mathrm{MS}, 0.1 \mathrm{wt} \%$ PFS and $0.1 \mathrm{wt} \%$ PAC water-soluble working liquid respectively.

\subsection{Standard Jar-Test Trial and Turbidity Measurements}

$6 \mathrm{~L}$ of raw water was equally put into six beakers marked from 1 to 6 . The corresponding amount of coagulant was added, and beaker was put into a Jar-test apparatus (MY3000-6C). Stirring for 2 minutes at different high speed, 10 min slow mixing at different speed and $30 \mathrm{~min}$ of sedimentation, extracting the supernatant fluid from the center of the baker, $2 \mathrm{~cm}$ from surface to determine the concentration of $\mathrm{Al}^{3+}$ with Aluminum ion concentration detector HANNA HI93712 which was supplied by HANNA Instruments in Italy and turbidity in water samples was measured with a turbidimeter which was also supplied by HANNA Instruments.

Trials with different coagulant concentrations were carried out, varying $\mathrm{pH}$ conditions between 5 and 9 . And difference of dosage and/or compounding ratio cause difference of $\mathrm{pH}$ variation through the coagulation process.

\section{Results and Discussion}

\subsection{Confirming the Optimal Formule of the Composite Coagulant}

The orthogonal experimental was conducted to confirm the optimum formule of the composite coagulant. Table 2 was the orthogonal layout of the composite coagulant. Table 3 was the results of the orthogonal experimental. $\mathrm{k}_{1}, \mathrm{k}_{2}, \mathrm{k}_{3}$ were the mean removal efficiencies of $\mathrm{Al}^{3+}$ each factor under three levels. And $k_{\mathrm{i}}, \mathrm{k}_{\mathrm{ii}}, \mathrm{k}_{\mathrm{iii}}$ were the mean removal efficiencies of turbidity each factor under three levels. As shown in Table 3, the optimum formula was $\mathrm{A}_{2} \mathrm{~B}_{2} \mathrm{C}_{2}$ on removing $\mathrm{Al}^{3+}$ and was $\mathrm{A}_{2} \mathrm{C}_{2} \mathrm{~B}_{2}$ on removing turbidity.

Table 3 showed that the removal rate of and the concentration of aluminum ion and turbidity achieved $71.3 \%$ and $97.2 \%$ respectively by using $\mathrm{A}_{2} \mathrm{~B}_{2} \mathrm{C}_{2}$. So the best proportion of this coagulant was $\mathrm{V}(0.1 \mathrm{wt} \%$ PAFC): $\mathrm{V}$ (0.001 wt\% CTS): $\mathrm{V}(3 \mathrm{wt} \% \mathrm{MS})=25: 6: 8$.

\subsection{Effect of Stirring Speed}

The stirring speed can change the hydraulic condition so that it will affect the coagulation effect. The process of flocculating can be divided into two stages: mixture and reaction [12]. The stirring speed was critical to the formation of flocs in the two stages. A series of tests were

Table 2. Orthogonal layout of the composite coagulant.

\begin{tabular}{cccc}
\hline Factors & $\begin{array}{c}\text { A (dosage of } \\
0.1 \mathrm{wt} \% \\
\left.\mathrm{PAF} / \mathrm{mg} \cdot \mathrm{L}^{-1}\right)\end{array}$ & $\begin{array}{c}\text { B (dosage of } \\
0.001 \mathrm{wt} \% \\
\left.\mathrm{CTS} / \mathrm{mg} \cdot \mathrm{L}^{-1}\right)\end{array}$ & $\begin{array}{c}\mathrm{C}(\text { dosage of } \\
3 \mathrm{wt} \% \\
\left.\mathrm{MS} / \mathrm{mg} \cdot \mathrm{L}^{-1}\right)\end{array}$ \\
\hline Level 1 & 4 & 1.0 & 1.4 \\
Level 2 & 5 & 1.2 & 1.6 \\
Level 3 & 6 & 1.4 & 1.8 \\
\hline
\end{tabular}

Table 3. Orthogonal layout of the composite coagulant and its analysis.

\begin{tabular}{cccccc}
\hline No. & A & B & C & $\begin{array}{c}\text { Removal rate } \\
\text { of } \mathrm{Al}^{3+}(\%)\end{array}$ & $\begin{array}{c}\text { Removal rate } \\
\text { of turbidity (\%) }\end{array}$ \\
\hline 1 & 1 & 1 & 1 & 61.5 & 86.9 \\
3 & 2 & 2 & 2 & 71.3 & 97.2 \\
4 & 3 & 3 & 3 & 68.1 & 87.4 \\
5 & 2 & 3 & 1 & 70.7 & 88.5 \\
6 & 3 & 1 & 2 & 69.4 & 90.7 \\
7 & 1 & 3 & 2 & 69.5 & 87.1 \\
8 & 2 & 1 & 3 & 61.4 & 89.4 \\
9 & 3 & 2 & 1 & 60.2 & \\
$\mathrm{k}_{1}$ & 201.7 & 188.5 & 191.1 & & \\
$\mathrm{k}_{2}$ & 202.1 & 202.2 & 206.4 & & \\
$\mathrm{k}_{3}$ & 193.9 & 207.0 & 200.2 & & \\
$\mathrm{R}$ & 8.200 & 18.50 & 15.30 & & \\
$\mathrm{k}_{\mathrm{i}}$ & 265.3 & 259.4 & 269.9 & & \\
$\mathrm{k}_{\mathrm{ii}}$ & 273.3 & 278.0 & 274.2 & & \\
$\mathrm{k}_{\mathrm{iii}}$ & 266.8 & 268.0 & 261.3 & & \\
$\mathrm{R}$ & 8.000 & 18.60 & 12.90 & & \\
\hline & & & & & \\
\hline & & & & \\
\hline
\end{tabular}


conducted to study the coagulation effectiveness of the composite coagulant under various stirring speed. Figure 1 showed the effect of rapid stirring speed. And at the rate of $180 \mathrm{r} / \mathrm{min}$ the removal rate of $\mathrm{Al}^{3+}$ and turbidity achieved $70.5 \%$ and $96.9 \%$, respectively that reached the highest level. Figure 2 showed the effect of slow stirring speed. And the rate of $60 \mathrm{r} / \mathrm{min}$ the removal rate of $\mathrm{Al}^{3+}$ and turbidity achieved $69.5 \%$ and $97.1 \%$, respectively that reached the highest level. The reasons could be explained by the mechanism of coagulation, on one hand, the composite coagulant reacted with substance which consumed oxygen directly and formed flocs. On the other hand, composite coagulant adsorbed the substance in the raw water by the function of bridging and net-capture. Therefore, it is requires an appropriate stirring intensity to prevent the breaking of formed particles, and avoid to reducing the removal rate of $\mathrm{Al}^{3+}$ and turbidity.

\subsection{Effect of Stirring Time}

A series of tests were conducted under various stirring time to determine the influence of stirring time to coagulation effect. Figure 3 showed the influence of the rapid stirring time. And the highest removal of $\mathrm{Al}^{3+}$ and turbidity reached $71.0 \%$ and $97.1 \%$ respectively when slow stirring for $2 \mathrm{~min}$. Figure 4 showed the influence of the slow stirring time. And the removal rate of $\mathrm{Al}^{3+}$ and turbidity reached the highest level which was $68.5 \%$ and $96.5 \%$ respectively when slow stirring for $10 \mathrm{~min}$. It was because that the mixing stage should at the rapid stirring speed in the coagulation process so that coagulant would spread into the water rapidly and evenly as well as made colloid particles to coagulation. As coagulation and formation of fine aggregate were completed in a few minutes, it would break up the formed fine aggregate and

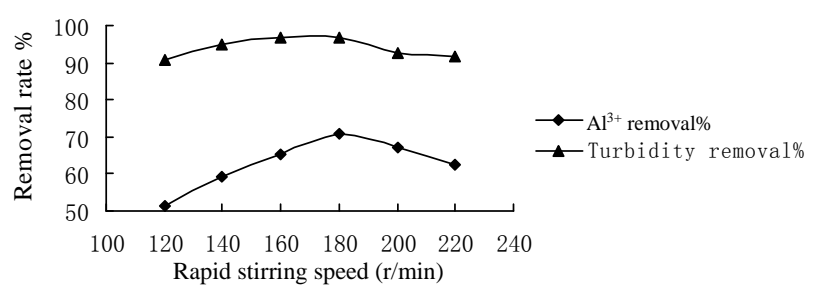

Figure 1. Influence of rapid stirring speed on coagulation effect.



Figure 2. Influence of slow stirring speed on coagulation effect.

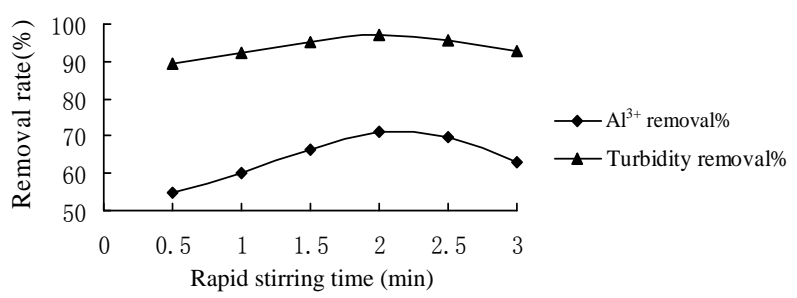

Figure 3. Influence of rapid stirring time on coagulation effect.

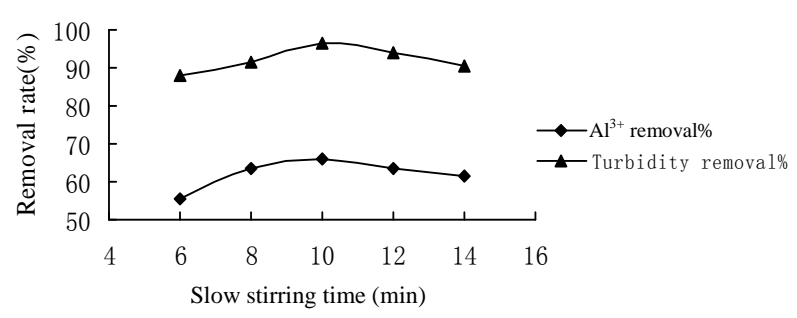

Figure 4. Influence of slow stirring time on coagulation effect.

affected interpretive coagulation if the stirring time was too long.

\subsection{Effect of Temperature}

As is presented in Figure 1, trials with different coagulation temperature were carried out. Treating the raw waters with PCS $7.8 \mathrm{mg} \cdot \mathrm{L}^{-1}$. The temperature changed from $10^{\circ} \mathrm{C}$ to $40^{\circ} \mathrm{C}$. Although temperature increases that effectiveness of the process tends to be lower, the turbidity removal level is still higher than $80 \%, \mathrm{Al}^{3+}$ removal level is still higher than $60 \%$.

\subsection{Effect of $\mathrm{pH}$}

Trials with different coagulant concentrations were carried out, varying $\mathrm{pH}$ conditions between 5 and 8 . Results of the trials are shown in Figure 6. With the change of the $\mathrm{pH}$, the removal of turbidity changed little. And the highest turbidity removal rate achieved $97.2 \%$ at $\mathrm{pH} 7$, when the dosage of PCS was $7.8 \mathrm{mg} / \mathrm{L}$.

\subsection{Raw Water Treated with Different Coagulants}

Several experiments of surface water clarification were carried out with four coagulants agents: PAFC, PFS, PAC and PAFC. Doses of $6.2 \mathrm{mg} / \mathrm{L}$ were added of each coagulant agent. The graphic presents the turbidity reduction in river raw water after a standard Jar-test procedure. As Figure 7 shows, the lever of turbidity and aluminium ion removal is quite similar in the case. And PCS presented higher performance in turbidity and aluminium ion removal, as is evident from Figure 7. 


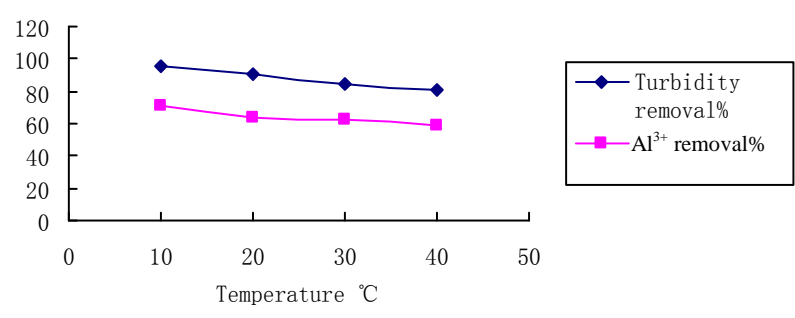

Figure 5. Temperature influence on turbidity removal with PCS. Coagulant dosage: $7.8 \mathrm{mg} / \mathrm{L}$, natural $\mathrm{pH}$. Initial turbidity: 127 NTU.

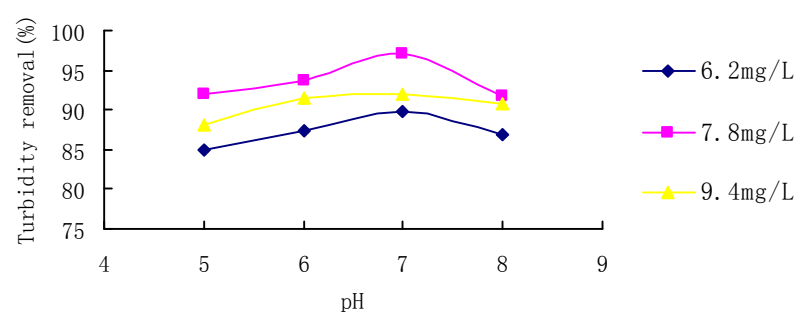

Figure 6. pH influence on turbidity removal in room temperature. Initial turbidity: 127 NTU.

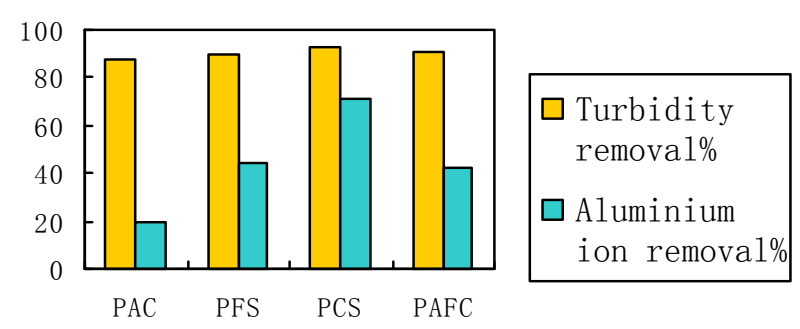

Figure 7. Aluminium ion and turbidity removal of the raw water treated by 4 different coagulants respectively. Coagulant dosage: $5.5 \mathrm{mg} / \mathrm{L}, 20^{\circ} \mathrm{C}$, neutral $\mathrm{pH}$.

\subsection{The Mechanism of Coagulation Analyses}

By copolymerization of the cheap ferric chloride and the aluminum chloride, PAFC is manufactured. So it holds concurrently the coagulation properties of aluminum salt and ferric salt. Ferric chloride and aluminum chloride [12] occurred in water treatment includes two major reactions, such as hydrolysis and polymerization. Colloid particles in water can strongly absorb all kinds of product associated with hydrolysis and polymerization such as the aluminum ions, ferric ion and multinuclear hydroxyl complex ion. Absorbed positively charged multinuclear hydroxyl complex ion can compress the double electrode layer and decrease the electrokinetic potential while promotes bridging. Multinuclear polymer is absorbed by more than two colloid particles in the same time, or bridge between two or more colloid particles to form the flocs. These all belong to colloid particles aggregation. Coagulant finally formed the high polymerization $\mathrm{Al}(\mathrm{OH})_{3}$ or $\mathrm{Fe}(\mathrm{OH})_{3}$, promoting coagulation progress.

The molecular chain of CTS includes a large number of hydroxyl groups, it can form hydrogen bond with the substances contained $-\mathrm{NH}_{2}$ and $-\mathrm{COOH}$ groups such as amino acid in water, which is able to absorb and sediment the substances so as to remove the organics and improve the removal rate of COD [13-15].

Since modified starch [16] has good effect of adsorption, CTS play the role of bridge, and electrification neutralize effect of PAFC, and compound using them together would achieve "synergistic, mutual complementarity". It can make small micelles in the solution condense together to form bigger and more compact flocs that resulted in enhanced degree of polymerization and cohesion, so the efficiency of adsorption and coagulation of the coagulant are greatly increased.

In the water the aluminum content of modified starch will be far less polymerization $\mathrm{AlCl}_{3}$. Moreover, the modified starch coagulants and chitosan coagulant have outstanding effect of absorbing and chelating metal ions such as aluminum ions. So this kind of "low aluminum" characteristic of the composite coagulant is determined by its composition and coagulation properties. It is also because of this "low aluminum" character, the new coagulant greatly reduced secondary pollution in water treatment process compared with the traditional coagulant.

\section{Conclusions}

The new composite coagulant for treating drinking water was prepared by using PAFC, CTS and modified starch. Results indicated that the best proportion of this coagulant was $\mathrm{V}(0.1 \mathrm{wt} \%$ PAFC): $\mathrm{V}(0.001 \mathrm{wt} \% \mathrm{CTS}): \mathrm{V}(3 \mathrm{wt} \%$ modified starch) $=25: 6: 8$. Treating per $1 \mathrm{~L}$ raw waters with $0.1 \mathrm{wt} \%$ PAFC $5 \mathrm{~mL}, 0.001 \mathrm{wt} \%$ CTS $1.2 \mathrm{~mL}$ and 3 wt\% modified starch $1.6 \mathrm{~mL}$ respectively. Due to high coagulation and adsorption ability of the organic polymer, under the same condition, the removal rate of SS of this composite coagulant was increased by $5.17 \%$ compared with the conventional coagulant PAC. Due to the favorable effect of chitosan and the modified starch for adsorbing and immeshing metal ion, the removal rate of the $\mathrm{Al}^{3+}$ mass was highly increased by using the novel coagulant. By the way, the concentration of $\mathrm{Al}^{3+}$ in the effluent decreased by $51.1 \%$ with the novel composite coagulant than the traditional coagulant.

In conclusion, reagent cost of this coagulant is low, and treatment effect is good. Besides, its "low aluminum" characteristics reduce the harm to human body. So the novel composite coagulant prepared by ourselves can be widely used in drinking water treatment field in china.

\section{Acknowledgements}

This project was supported by Ministry of Science and Technology in SME Technology Innovation Foundation 
of China and Department of Science and Technology in Hubei province, Science and Technology Research Foundation of China. We thank those who provide guidance and assistance.

\section{REFERENCES}

[1] N. A. Kabbashi, A. H. Nour, S. A. Muyibi, et al., "Development of a Wastewater Treatment System for Chromium Removal Using Chitosan,” International Journal of Chemical Technology, Vol. 1, No. 2, 2009, pp. 44-51. doi:10.3923/ijct.2009.44.51

[2] Z. Yousefi and M. A. Zazouli, "Removal of Heavy Metals from Solid Wastes Leachates Coagulation-Flocculation Process,” Journal of Applied Sciences, Vol. 8, No. 11, 2008, pp. 2142-2147. doi:10.3923/jas.2008.2142.2147

[3] F. Renault, B. Sancey, P. M. Badot, et al., "Chitosan for Coagulation/Flocculation Processes-An Eco-Friendly Approach,” European Polymer Journal, Vol. 45, No. 4, 2009, pp. 1337-1348.

[4] T. J. Brown and M. B. Emelko, "Chitosan and Metal Salt Coagulant Impacts on Cryptosporidium and Microsphere Removal by Filtration,” Water Research, Vol. 43, No. 2, 2009, pp. 331-338. doi:10.1016/j.watres.2008.10.035

[5] P. Flaten, “Aluminium as a Risk Factor in Alzheimer's Disease with Emphasis in Drinking Water," Brain Research Bulletin, Vol. 55, No. 2, 2001, pp. 187-196. doi:10.1016/S0361-9230(01)00459-2

[6] W. Y. Yang, J. W. Qian and Z. Q. Shen, “A Novel Flocculant of $\mathrm{Al}(\mathrm{OH})_{3}$-Polyacrylamide Ionic Hybrid,” Journal of Colloid and Interface Science, Vol. 273, No. 2, 2004, pp. 400-405. doi:10.1016/j.jcis.2004.02.002

[7] H. Tang and B. Shi, "The Characteristics of Composite Flocculants Synthesized with Inorganic Polyaluminium and Organic Polymers," Chemical Water and Wastewater Treatment VII Proceedings of the 10th Gothenburg Symposium, Gothenburg, 17-19 June 2002, pp. 17-28.

[8] S. L. Y. Ling, C. Y. Yee and H. S. Eng, "Removal of a
Cationic Dye Using Deacetylated Chitin (Chitosan)," Journal of Applied Sciences, Vol. 11, No. 8, 2011, pp. 1445-1448. doi:10.3923/jas.2011.1445.1448

[9] S. M. Jamil, M. W. Ali, A. Ripin, et al., "Metals Removal from Recovered Base Oil Using Chitosan Biopolymers," Journal of Applied Sciences, Vol. 10, No. 21, 2010, pp. 2725-2728. doi:10.3923/jas.2010.2725.2728

[10] D. Fan, X. M. Zhu, M. Xu, et al., "Adsorption Properties of Chromium (VI) by Chitosan Coated Montmorillonite," Journal of Biological Sciences, Vol. 6, No. 5, 2006, pp. 941-945. doi:10.3923/jbs.2006.941.945

[11] S. A. Ali, S. Pal and R. P. Singh, "Coagulation Performance of Modified Chitosan in an Aqueous Suspension," Journal of Applied Polymer Science, Vol. 118, No. 5, 2010, pp. 2592-2600.

[12] B. Gao, Q. Yue and J. Miao, "Evaluation of Polyaluminium Ferric Chloride (PAFC) as a Composite Coagulant Forwater Andwastewater Treatment," Water Science and Technology, Vol. 47, No. 1, 2002, pp. 127-132.

[13] W. Jing, X. Y. Yuan and H. Y. Yan, "The Study on Adsorption Performance of Modified Starch for Organic Pollutants," Journal of Jinan University (Natural Science Edition), Vol. 22, No. 1, 2008, pp. 72-73.

[14] A. Jideowno, J. M. Okuo and P. O. Okolo, "Sorption of Some Heavy Metal Ions by Chitosan and Chemically Modified Chitosan,” Trends in Applied Sciences Research, Vol. 2, No. 3, 2007, pp. 211-217. doi:10.3923/tasr.2007.211.217

[15] M. S. Rana, M. A. Halim, S. Safiullah, et al., "Removal of Heavy Metal from Contaminated Water by Biopolymer Crab Shell Chitosan,” Journal of Applied Sciences, Vol. 9, No. 15, 2009, pp. 2762-2769. doi:10.3923/jas.2009.2762.2769

[16] N. Bleiman and Y. G. Mishael, "Selenium Removal from Drinking Water by Adsorption to Chitosan-Clay Composites and Oxides: Batch and Columns Tests,” Journal of Hazardous Materials, Vol. 183, No. 1-3, 2010, pp. 590595. doi:10.1016/j.jhazmat.2010.07.065 